\title{
PERFORMANCE TESTING OF GROUT-BASED WASTE FORMS FOR THE SOLIDIFICATION OF ANION EXCHANGE RESINS
}

\author{
I. L. Morgan \\ W. D. Bostick \\ Chemical Technology Division \\ at the Oak Ridge National Laboratory \\ and Technical Division \\ at the K-25 Site
}

Date Published-October 1990

NOTICE: This document is an internal Energy Systems publication of a paper recently submitted for publication in the proceedings of an American Society for Testing and Materials (ASTM) conference. The format and style of this document are those specified by ASTM.

Prepared for

The DOE Office of Uranium Enrichment

Budget Activity Number 1001214

MARTIN MARIETTA ENERGY SYSTEMS, INC.

operating the

Oak Ridge National Laboratory

Oak Ridge Y-12 Plant

Oak Ridge Gaseous Diffusion Plant Paducah Gaseous Diffusion Plant

for the

U.S. DEPARTMENT OF ENERGY

under contract DE-AC05-84OR21400 
ABSTRACT AND KEY WORDS $\ldots \ldots \ldots \ldots \ldots \ldots \ldots \ldots$

INTRODUCTION $\ldots \ldots \ldots \ldots \ldots \ldots \ldots \ldots \ldots \ldots \ldots \ldots$

PURPOSE AND SCOPE OF THE STUDY .............. 2

MATERIALS TESTED $\ldots \ldots \ldots \ldots \ldots \ldots \ldots \ldots \ldots \ldots \ldots$

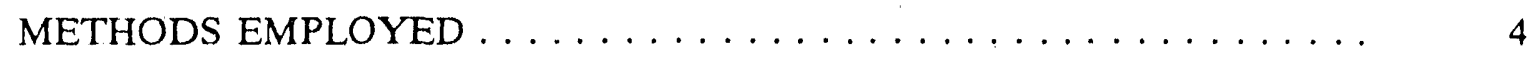

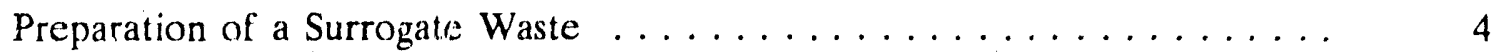

Preparation of the Grout Samples . . . . . . . . . . . . . . . 5

Preparation of the Vinyl Ester Styrene Waste Form . . . . . . . . . . 6

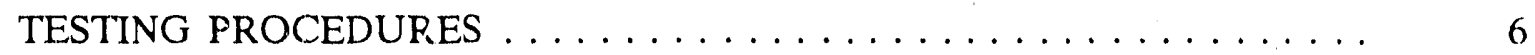

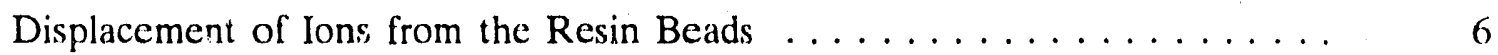

Leachability Testing Using the Cured Grout Specimeris . . . . . . . . . . . 7

Freezing/Thawing Testing and Wetting/Drying Testing $\ldots \ldots \ldots \ldots 7$

Immersion Testing $\ldots \ldots \ldots \ldots \ldots \ldots \ldots \ldots \ldots \ldots$

Fire Accideni Scenario Testing $\ldots \ldots \ldots \ldots \ldots \ldots \ldots$

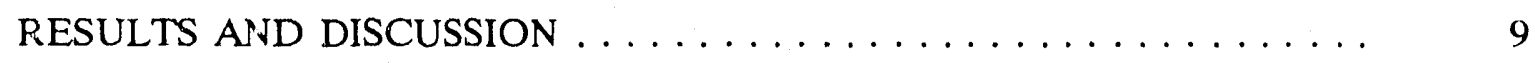

Displacement of Ions from the Resin Beads . . . . . . . . . . . .

Leachability Testing Using the Cured Grout Specimens . . . . . . . . . . . 9

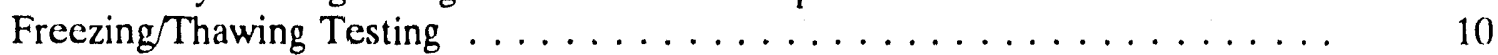

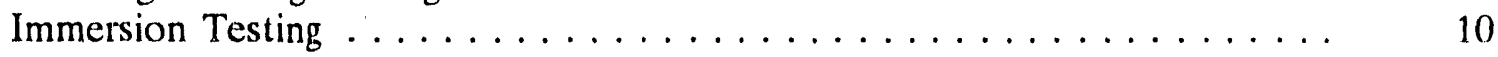

Wetting/Drying Testing . . . . . . . . . . . . . . . . . . . . . . 12

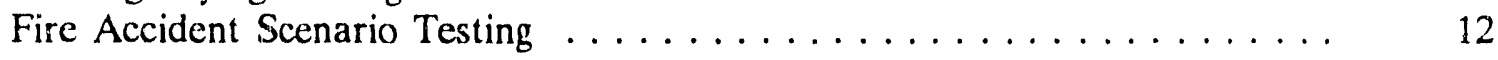

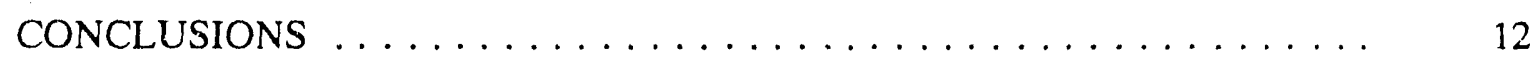

ACKNOWLEDGMENTS $\ldots \ldots \ldots \ldots \ldots \ldots \ldots \ldots \ldots \ldots \ldots$

REFERENCES ........................ 15 


\title{
PERFORMANCE TESTING OF GROUT-BASED \\ WASTE FORMS FOR THE SOLIDIFICATION \\ OF ANION EXCHANGE RESINS
}

\author{
I. L. MORGAN \\ Chemical Technology Division \\ Oak Ridge National Laboratory \\ W. D. BOSTICK \\ Technical Division \\ Applied Technology Organization \\ Martin Marietta Energy Systems, Inc. \\ Oak Ridge, Tennessee 37831-7272
}

\begin{abstract}
The solidification of spent ion exchange resins in a grout matrix as a means of disposing of spent organic resins produced in the nuclear fuel cycle has many advantages in terms of process simplicity and economy, but associated with the process is the potential for water/cement/resins to interact and degrade the integrity of the waste form solidified. Described in this paper is one possible solution to preserving the integrity of these solidified waste forms: the encapsulation of beaded anion exchange resins in grout formulations containing ground granulated blast furnace slag, Type I-II (mixed) portland cement, and additives (clays, amorphous silica, silica fume, and fly ash). The results of the study reported herein show the cured waste form tested has a low leach rate for nitrate ion from the resin (and a low leach rate is inferred for Tc-99) and acceptable durability as assessed by the water immersion and freezing/thawing test protocols (but often not as assessed by a wetting/drying test protocol). The results also suggest a tested surrogate waste form prepared in vinyl ester styrene binder performs satisfactorily against the wetting/drying criterion, and it should offer additional insight into future work on the solidification of spent organic resins.
\end{abstract}

KEY WORDS: cement waste forms, durability testing, ion errhange resins, solidification, vinyl ester styrene waste forms, wetting/drying test.

\footnotetext{
Operated by Martin Marietta Energy Systems, Inc., for the U.S. Department of Energy under contract DE-AC05-84OR21400.
} 


\section{PERFORMANCE TESTING OF GROUT-BASED \\ WASTE FORMS FOR THE SOLIDIFICATION \\ OF ANION EXCHANGE RESINS}

\section{Introduction}

Organic-based ion exchange resins (IERs) are frequently used in the nuclear power industry for removing radioactive impurities in aqueous process and waste streams. They also are the most important waste in terms of "becquerels" generated in nuclear power plants-especially pressurized water reactors-and they contribute a large annual waste volume for disposal. ${ }^{\prime}$

The direct incineration of spent organic resins would appear to be an attractive disposal option (especially for volume and mass reduction), ${ }^{2}$ but this process results in a higher dose rate in the ash, and it imposes a higher purification efficiency for the exhaust gas for minimizing radioactive emissions. ${ }^{3}$ The scarcity of permitted radwaste incinerators also severely limits the application of this option. In practice, IERs are generally conditioned into stable waste forms by incorporation in suitable inert matrices [e.g., cement, bitumen/asphalt, or (to a lesser extent, due to process economics) synthetic organic polymer (including epoxy resins, polyesters, styrene polymer, polyethylene, polyvinyl chloride, urea-formaldehyde, phenol-formaldehyde, polyurethane, and polymethyl methacrylate)]. ${ }^{l, 4}$

Cementation is the simplest, most frequently used, and often the most adequate method for stabilizing (solidifying) spent IERs. "It has numerous advantages in terms of cost, convenience, and performance, but it is not without criticism. ${ }^{6}$ Problems with the concrete encapsulation of spent IERs are related to both the cement solidification process itself

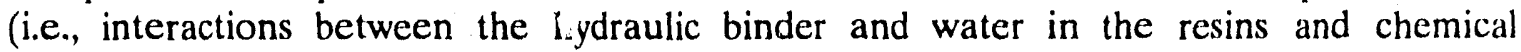
interactions between the immobilized ions and the ions in the cement paste $)^{\text {a. }}$ and to the utilization of the process (mixing, process control, variable waste feed composition, etc.). ${ }^{8}$

Cementation process interactions have, on occasion, resulted in poor mechanical properties, waste form destruction upon immersion in water, and altered setting rates. An undesirable water/cement/resin interaction is the potential for drying out (and contraction) of the resin during excessively exothermic cement hydration reactions, with subsequent destructive expansive swelling of the resins upon immersion of the waste form in water; ${ }^{8}$ this problem is more prevalent for cation resins arid mixed bed resins solidified in an ordinary portland cement (OPC) binder ${ }^{\circ}$ and is enhanced $r$., the continuous replacement of monovalent ions on the cation resin by $\mathrm{Ca}^{+2}$ and $\mathrm{Al}^{+3}$ from the cement that may cause a further volume increase in the resin. ${ }^{10}$

Displacement from the spent resin of chemicals that alter cement sct rate (e.g., borates, which retard set) and certain organic chelates (e.g., citrate or picolinate) that can complex free $\mathrm{Ca}^{+2}$ from the grout or enhance radionuclide mobility can also cause problems when cementation is the method used to stabilize/solidify spent organic resins. 
With the proper selection of a binder, adequate knowledge of the waste process chemistry, and quality control guidance obtained through laboratory-scale testing and pilot scale confirmation, most undesirable water/cement/resin interactions can be eliminated or controlled within acceptable limits. Beneficial admixtures can be applied in many cases (e.g., soluble silica to accelerate set, a fluidizing agent to facilitate mixing, clays to control free water or impart selective sorptive properties, etc.), and binder blends can be selected that evolve less heat or evolve heat more slowly. ${ }^{8}$ Binder blends in which a large proportion of the OPC is replaced with ground granulated blast furnace slag (BFS) have been demonstrated to minimize the potential for the formation of expansive phases, ${ }^{1,7,8,11}$ and they allow relatively high volumetric incorporation of resin waste in the waste form [e.g., as great as 50 to 75 percent $(\mathrm{v} / \mathrm{v})]^{1,8,11}$

\section{Purpose and Scope of the Study}

For several years, spent organic resins have been stored at the U.S. Department of Energy's Portsmouth Gaseous Diffusion Plant (PORTS) in Piketon, Ohio, pending the selection of an acceptable option for disposing of this waste. ${ }^{12.13}$ The resin waste that needs to be disposed of is beaded strongly basic anion exchange resin (Dowex-SBR) used at the Portsmouth plant for removing the Technetium-99 isotope (as the pertechnetate ion, $\mathrm{TcO}_{4}{ }^{-}$) from neutralized decontamination waste containing nitrate ion. ${ }^{14,15} \mathrm{Tc}-99$ undergoes radioactive decay by low-energy $(0.29 \mathrm{MeV})$ beta emission, with a half-life of 213,000 years. Spent resin from the PORTS process typically contains 0.1 to $1.0 \mathrm{mg} \mathrm{Tc}-99$ per gram of wet resin (about $0.8-8.0 \mu \mathrm{Ci} / \mathrm{cm}^{3}$ ); a small sample of spent resin from the PORTS process obtained for the study had a surface gross beta activity of about 154,000 disintegrations/ $\min / 100 \mathrm{~cm}^{2}$.

Our e.forts early on in this study were influenced by other work being reported on the solidification of spent organic resins. Preliminary work had been reported by Dyer and McGinnes, ${ }^{16}$ who demonstrated that technetium-laden organic anion exchange resins could be successfully encapsulated in binders containing $90 \mathrm{BFS}: 10 \mathrm{OPC}$ and $50 \mathrm{BFS}: 50 \mathrm{OPC}$ $(w / w)$ and in a polymer-modified cement. The chief performance criterion used in their investigation was the loss of compressive strength after immersion in simulated sea water for one month; there was little change noted in the structural integrity of the cement forms after immersion, although it was found that small amounts of surface beads and cement flakes were lost in the waste forms containing 60 percent resin waste loadings.

We also knew that grout containing BFS has a residual reduction potential ${ }^{17}$ and has been demonstrated to significantly decrease the leachability of Tc.99, presumably by its ability to reduce $\mathrm{Tc}(\mathrm{VII})$ to the less soluble $\mathrm{Tc}(\mathrm{IV})$ form, with possible mineralogical fixation. ${ }^{14,18,19,20}$ Thus, we believed that a BFS grout might have an additional benefit for the fixation of the Tc-laden resin on-site at the Portsmouth plant.

The solidified resin waste form properties that were of concern to us in our study are summarized in Table 1 (from Ref. 6). Specifically, we were interested in the waste form's ability to (1) form a monolithic waste form with adequate compressive strength for an hypothesized disposal scenario, (2) have adequate stability toward radiation, (3) resist biodegradation, (4) retard radionuclide leachability, (5) demonstrate probable long-term 
TABLE 1—Solidified product guidance.

\begin{tabular}{|c|c|c|}
\hline Tests & Methods & Criteria \\
\hline Compressive Strength & ASTM C39 or D1074 & $414 \mathrm{kPa}(60 \mathrm{psi})$ \\
\hline Radiation Stability & (See 1983 TP) & $\begin{array}{l}414 \mathrm{kPa} \text { comp. str. } \\
\text { after } 10 \mathrm{E}+8 \mathrm{rads}\end{array}$ \\
\hline Biodegradation & ASTM G21 \& G22 & $\begin{array}{l}\text { No growth }{ }^{b} \text { and } \\
\text { comp. str. }>414\end{array}$ \\
\hline $\mathrm{kPa}$ & & \\
\hline Leachability & ANS 16.1 & Leach index of $\geq 6$ \\
\hline Immersion & (See $1983 \mathrm{TP}$ ) & $\begin{array}{l}414 \mathrm{kPa} \text { comp. str. } \\
\text { after } 90 \text { days }\end{array}$ \\
\hline Thermal Cycling & ASTM B553 & $\begin{array}{l}414 \mathrm{kPa} \text { comp. str. } \\
\text { after } 30 \text { cycles }\end{array}$ \\
\hline Free Liquid & ANS 55.1 & $0.5 \%$ \\
\hline Full-scale & (See 1983 TP) & $\begin{array}{l}\text { Homogeneous and } \\
\text { correlates to lab } \\
\text { size test results }\end{array}$ \\
\hline
\end{tabular}

${ }^{a}$ The 1983 Branch Technical Position (TP) paper calls for a minimum compressive strength of $345 \mathrm{kPa}(50 \mathrm{psi})$. This has been raised to $414 \mathrm{kPa}$ (60 psi) to accommodate an increased maximum burial depth at Hanford of $55 \mathrm{ft}$ (from $45 \mathrm{ft}$ ) as defined by the U.S. Nuclear Regulatory Commission publication entitled Draft Regulatory Guide on Low-Level Waste Form Stability (a proposed revision to 10 CFR 61, "RG LLW Form Stability," Rev. 4, October 1986).

${ }^{b}$ The 1983 Branch TP calls for a multi-step procedure for biodegradation testing: if observed culture growth rated "greater than 1 " is observed following a repeated ASTM G21 test, or any growth is observed following a repeated ASTM G22 test, longer term testing (for at least six months) is called for, using the "Bartha-Pramer Method." From this test, a total weight loss extrapolated for full-size waste forms to 300 years should produce less than a 10 percent loss of total carbon in the sample.

durability as assessed by water immersion and thermal cycling testing procedures, and (6) contain free water associated with the resin.

After a review of the literature, we determined that IER waste form durability would be a key issue. We therefore focused our testing on the durability testing of a surrogate waste (Dowex SRB, converted to the nitrate form) solidified in binder blends containing various proportions of BFS, OPC, ASTM Type F fly ash, amorphous silica, and clays (bentonite or attapulgite). After a 43-day cure time, our samples were subjected to the ANSI/ANS-16.1 leach test procedure ${ }^{2 l}$ (to determine the mass transport properties for nitrate ion), a 90-day (and beyond) immersion test using distilled water, and tests to evaluate resistance to cycles of freezing/thawing and wetting/drying procedures. The latter two testing procedures were developed at the Alberta Environmental Centre, Alberta, 
Canada, and are outlined in draft testing protocols developed by ASTM task group D34.02.07.

In addition to testing the cured waste form we had prepared for the study, we also decided to test a waste form prepared by a commercial vendor by solidifying surrogate IER waste in a vinyl ester styrene matrix. Sections prepared from this waste form were subjected to wetting/drying testing and fire accident scenario testing by immersing the waste form in burning fuel oil for an interval of $10 \mathrm{~min}$.

\section{Materials Tested}

Virgin Dowex SRB-OH resin beads (the hydroxide form of Dowex-1X8) were received from the PORTS facility as a subsample of the material used in their Tc-removal process. The as-received drained resin had approximately a Gaussian particle size distribution, with a mean diameter of $610 \pm 180 \mu \mathrm{m}$ (mean \pm 1 standard deviation) and a moisture content of about 54 percent $(w / w)$. The drained material that was converted to the nitrate form had a mean diameter of $540 \pm 220 \mu \mathrm{m}$.

The attapulgite-150 drilling mud (a fibrous, adsorbent clay) was obtained from Mountaineer Mud and Chemical Co., Charleston, West Virginia. And bentonite, a gel forming smectite clay, was obtained from Fisher Scientific Co., Fair Lawn, New Jersey (Product No. B-235).

The ground granulated blast furnace slag was obtained from Standard Slag Co., Canfield, Ohio. Portland Type I-II cement (ASTM C 150-85) was obtained from Ash Grove West, Seattle, Washington. ASTM class F fly ash was obtained from Amerizan Fly Ash Co., Des Plaines, Illinois. The typical composition of these materials is given in the publication entitled Blast Furnace Slag-Cement Blends for the Immobilization of Technetium-Containing Wastes. ${ }^{18}$

Amorphous silica grade 1240 was obtained from Illinois Minerals Co., Cairo, Illinois. This material has a lognormal particle size distribution, with a median diameter of $6.4 \mu \mathrm{m}$ and a spread factor of 2.9 (Ref. 22). Silica fume mineral admixture, with pozzolanic and void-filling properties said to produce a relatively dense and impermeable grout product, was obtained from Master Builders, Cleveland, Ohio (Product No. MB-SF ${ }^{\star}$ ).

Sodium silicate solution $\left(43^{\circ}\right.$ Baume $\left.{ }^{\prime}\right)$ was obtained from Fisher Scientific (Product No. SS338-1).

\section{Mcthods Employed}

Preparation of a Surrogate Waste

The sample of spent resin we received from PORTS was not sufficient for our use in an extensive development effort. Instead what we needed was a larger quantity of a surrogate waste with primarily the same characteristics as the PORTS sample and leach rate 
properties no less conservative; for convenience, we elected to use a "cold" surrogate prepared using sodium nitrate solution, reasoning that nitrate ion would be more readily leached from the solidified resin than pertechnetate ion (vide infra).

We stirred $1 \mathrm{~L}$ of $1.25 \mathrm{~N}$ sodium nitrate solution and $500 \mathrm{~g}$ of moist Dowex SRB-OH resin for $2 \mathrm{~h}$ to achieve an equilibrium distribution of nitrate ion. The resin slurry was transferred to a Buchner funnel to remove excess nitrate solution. Nitrate ion in the filtrate was analyzed by ion chromatography to determine (by mass balance) the nitrate ion loading on the resin (typically, $0.1 \mathrm{~g}$ nitrate/g wet resin). The "cold" surrogate waste was stored in capped Teflon jars until ready for use.

\section{Preparation of the Grout Samples}

Predetermined amounts of the binder dry-blend ingredients (as listed in Table 2) were mixed in a " $V$ " (or twin-shell) blender for $4 \mathrm{~h}$ to ensure a homogeneous mixture. After binder homogenation, a known amount of dry-blend was placed in the mixing bowl (5-liter capacity) of a standard Hobart Model N-50 mixer. Next, a measured mass of the surrogate waste "wet" resin (containing about 50 percent moisture) and the required amount of reagent water were added, in that order. The contents of the bowl were mixed at low speed ( 140 revolutions per minute, or rpm) for $1 \mathrm{~min}$; then mixing was switcheci to medium speed (285 rpm) and continued for an additional minute. The mass ratios (w/w) for constituents added to the as-poured grout were as follows: dry-mix blend, 43.3 percent; reagent water, 39.4 percent; and drained resin, 17.3 percent. On a volumetric basis, the drained resin comprised approximately 40 percent ( $v / v$ ) of the waste form.

TABLE 2-Grout dry-blend formulations.

\begin{tabular}{|c|c|c|c|c|c|c|c|}
\hline \multirow[b]{2}{*}{ Component } & \multicolumn{7}{|c|}{ Binder Blend Composition, Weight \% } \\
\hline & $\begin{array}{c}\text { Blend } \\
\# 1\end{array}$ & $\begin{array}{l}\text { Blend } \\
\# 2\end{array}$ & $\begin{array}{c}\text { Blend } \\
\# 3\end{array}$ & $\begin{array}{c}\text { Blend } \\
\# 4\end{array}$ & $\begin{array}{c}\text { Blend } \\
\# 5\end{array}$ & $\begin{array}{c}\text { Blend } \\
\# 6\end{array}$ & $\begin{array}{c}\text { Blend } \\
\# 7\end{array}$ \\
\hline Blast Furnace Slag & 75 & 69 & 70 & 75 & 69 & 84.5 & 90 \\
\hline Type I-II Cement & 10 & 10 & 10 & 10 & 10 & 9.5 & 10 \\
\hline Bentonite Clay & 15 & 15 & & & & & \\
\hline Attapulgite Clay & & & 15 & 15 & 15 & & \\
\hline Amorphous Silica & & 6 & 5 & & & & \\
\hline Class F Fly Ash & & & & & 6 & & \\
\hline silica Fume & & & & & & 6 & \\
\hline
\end{tabular}

After the mixing process was completed, the resulting waste loaded grout paste was transferred to either stainless steel 2 -in. cube molds (previously coated with silicone lubricant to facilitate removal of the cubes after set) or cylinder molds fabricated from Teflon for use in the ANS-16.1 procedure. Grout samples were removed from their mold 
form after 3 days and placed in a curing chamber (with 100 percent relative humidity at ambient temperature) for about 45 days to complete the curing process.

Preparation of the Vinyl Ester Styrene Waste Form

The vinyl ester styrene process for radwaste disposal was developed by Dow Chemical Co. and is currently marketed by Diversified Technologies, Chestertown, Maryland, as the VERI process. The waste form tested in this investigation was prepared by the vendor using "cold" surrogate waste IER (nitrate form). The waste loading accomplished in this process is essentially 100 percent, since the binder simply fills the interstitial voids between the resin beads.

\section{Testing Procedures}

Displacement of Ions from the Resin Beads

In order to minimize contaminant leachability, we knew it would be desirable that the contaminant(s) of interest remain sorbed on the IER and not be displaced into the grout matrix porewater. Strongly basic anion exchange resin has a high affinity for nitrate and pertechnetate ions. ${ }^{14}$ Pertechnetate ion is especially strongly adsorbed and can be eluted only by ions with very high affinity for the resin, such as perchlorate and salicylate. ${ }^{23}$

We performed some preliminary investigations to determine the difficulty of displacing pertechnetate ion from spent Dowex SRB resin. Two-mL volumes of packed resin were prepared from slurried virgin resin loaded into $0.76-\mathrm{cm}$ ID disposable chromatographic columns, ${ }^{15}$ and $1 \mathrm{~mL}$ of a surrogate waste (containing about $11 \mu \mathrm{g} \mathrm{Tc}-99$ and $62 \mathrm{mg}$ $\left.\mathrm{NO}_{3}\right)^{14,15}$ was added and the column rinsed with distilled water. The resin retained $>98.5$ percent of the applied Tc-99 [equivalent loading: about $11 \mu \mathrm{g} \mathrm{Tc}-99 / \mathrm{g}$ resin (wet weight basis) or $25 \mu \mathrm{g} \mathrm{Tc}-99 / \mathrm{g}$ resin (dry weight basis), with a surface beta activity of about 18,000 disintegrations/min $/ 100 \mathrm{~cm}^{2}$ ]. Four bed-volume aliquots of various solutions were applied to the column (followed by 1 bed volume of distilled water rinse), and the eluted solutions were analyzed by liquid scintillation counting ${ }^{14}$ to determine the amount of Tc-99 disnlaced by the solutions. The solutions tested were as follows: $2 \mathrm{NHClO}_{4} ; 1 \mathrm{~N} \mathrm{HClO}_{4} ; 1 \mathrm{~N} \mathrm{NaClO}$; $1 \mathrm{~N} \mathrm{H}_{2} \mathrm{SO}_{4} ; 1 \mathrm{~N}$ sodium citrate; and $2 \mathrm{~N} \mathrm{NaOH}$.

We knew that nitrate ion is displaced from the resin during service by traces of pertechnetate ion ${ }^{t 5}$ and might be labile enough to undergo a small amount of ion exchange by the hydroxide or soluble silicate ions in the waste form porewater. In a batch test, $10 \mathrm{~g}$ of "cold" surrogate waste resin (containing $1.03 \mathrm{~g}$ sorbed nitrate ion) were exposed to $100 \mathrm{~mL}$ of dilute sodium silicate solution (containing $0.36 \mathrm{~g}$ soluble silicate) to determine the difficulty of displacing the nitrate ion from the resin. 
Leachability Testing Using the Cured Grout Specimens

The leachability of the nitrate in the solidified surrogate waste form was assessed using the ANSI/ANS-16.1 procedure, ${ }^{2 t}$ at ten replacement leachate collection intervals (a 30-day cumulative leach in demineralized water). This standard expresses the leaching data in terms of basic mass transport theory (diffusion from a semi-infinite medium) and then an "effective diffusivity" is determined for the constituents of interest.

$$
D=\pi\left[\frac{a_{n} / A_{0}}{(\Delta T)_{n}}\right]^{2}\left[\frac{V}{S}\right]^{2} \quad(T),
$$

where

$a_{n}=$ activity of a nuclide released from the sample during leaching interval $n$, corrected for radioactive decay,

$A_{0}=$ total activity of a given radionuclide in the sample at the beginning of thic leach test (i.c., after the initial 30-s rinse),

$(\Delta \tau)_{\mathrm{n}}=\tau_{\mathrm{n}}-\tau_{\mathrm{n} \cdot 1}$, duration of the $n$th leaching interval, $\mathrm{s}$,

$\mathrm{D}=$ effective diffusivity, $\mathrm{cm}^{2} / \mathrm{s}$,

$\mathrm{V}^{\prime}=$ volume of sample, $\mathrm{cm}^{3}$,

$\mathrm{S}=$ geometric surface area of the sample as calculated from measured dimensions, $\mathrm{cm}^{2}$,

$T=\left[0.5\left(\tau_{n}^{0.5}+\tau_{n-1}^{0.5}\right)\right]^{2}$, leaching time, representing the "mean time" of the leaching interval, $s$.

The negative logarithm of the average effective diffusivity (in $\mathrm{cm}^{2} / \mathrm{s}$ ) is the defined leachability index.

$$
L_{i}=\frac{1}{n} \sum_{1}^{n}\left[\log \left(\beta / D_{i}\right)\right]_{n}
$$

where $\beta$ is a defined constant $\left(1 \mathrm{~cm}^{2} / \mathrm{s}\right)$ and $D_{i}$ is the effective diffusivity of nuclide $i$ calculated from the test data.

Larger values for the leachability index we knew would be desirable, since they represent smaller values for contaminant diffusivicy (i.e., a lower value for contaminant release rate).

Freezing/Thawing Testing and Wetting/Drying Testing

Triplicate samples from each grout formulation were subjected to testing procedures designed to evaluate waste form durability. Specifically, the terts we performed were the freezing/thawing and wetting/drying test procedures developed at the Alberta Environmentai 
Centre and subsequently outlined in draft testing protocols developed by ASTM task group D34.02.07.

The freezing/thawing test involved freezing the sample at $-20^{\circ} \mathrm{C}$ for $24 \mathrm{~h}$, storing the sample at room temperature for $1 \mathrm{~h}$, and then immersing the sample in water chilled to $4^{\circ} \mathrm{C}$. The sample was allowed to reach room temperature while being immersed in the water for a period of $23 \mathrm{~h}$. After this immersion phase, the sample was removed from the water, any loose material washed from the sample into the water, and ihe sample transferred to a clean tared beaker for the start of the next cycle of testing. The mass loss of the sample was determined by evaporating the water from the beaker after removing the waste form and weighing the material left behind. The sample was subjected to twelve cycles of this test.

The wetting/drying test was similar to the freezing/thawing test procedure, except the sample was first dried at $60^{\circ} \mathrm{C}$, allowed to cool for $1 \mathrm{~h}$, then covered with room-temperature water for $23 \mathrm{~h}$.

A waste form's failing either the freezing/thawing or wetting/drying tests was based upon a criterion of a cumulative weight loss of greater than 20 percent (dry-weight basis) at any point in the procedure.

\section{Immersion Testing}

The cylindrical cured grout specimens were immersed in distilled water for a recommended 90 days (the time interval recommended in a $1983 \mathrm{NRC}$ Branch Technical Position paper, i.e., see Table 1) and then for a longer interval to determine any visible signs of degradation such as swelling or flaking. After approximately 200 days of immersion, duplicate specimens were subjected to compressive strength testing (ASTM procedure C39).

\section{Fire Accident Scenario Testing}

Due to the fact that the surrogate waste we studied contained a relatively high concentration of nitrate ion (a strong oxidant and a potential accelerant for combustion), we performed limited testing of the waste forms by subjecting them to a fuel oil fire for a 10 -min interval to simulate a possible transportation accident scenario.

The waste forms tested included a 2 -in. grout/resin cube (with a waste form density of $1.44 \mathrm{~g} / \mathrm{cm}^{3}$ ) and cylindrical sections (of approximately $4.6 \mathrm{~cm}$ in diameter by $3.4 \mathrm{~cm}$ in height and with a waste form density of $0.89 \mathrm{~g} / \mathrm{cm}^{3}$ ) of solidified VERI $/$ resin (vendor solidified samples of mixed-bed resins and SRB-NO $\mathrm{N}_{3}$. 


\section{Results and Discussion}

Displacement of Ions from the Resin Beads

The results of our preliminary testing to determine the difficulty of displacing pertechnetate ion from spent Dowex SRB resin showed these percents of Tc-99 displaced:

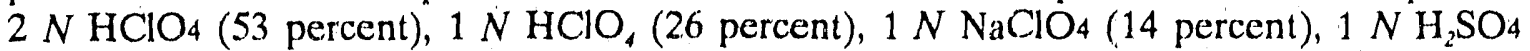
( 0.27 percent $), 1 \mathrm{~N}$ sodium citrate $(0.13$ percent $)$, and $2 \mathrm{~N} \mathrm{NaOH}(0.13$ percent $)$. Scidium silicate solution $(0.3 \mathrm{~N})$ displaced negligible Tc-99. These data indicate that sorbed pertechnetate inn is very difficult to displace from the resin and that little ion exchange with Tc should occur in the grout waste form porewater ( $\mathrm{pH}$ about 13).

The results of our testing to determine the difficulty of displacing nitrate ion from spent resin showed $4.7 \mathrm{E}-3 \mathrm{~mol}$ of alkaline soluble silicate displaced only $3.7 \mathrm{E}-4 \mathrm{~mol}$ of nitrate ion (6.3 percent of the nitiate applied to the resin), as determined by ion chromatographic analysis. This result suggests that nitrate ion would not readily be displaced from the resin in the grout waste form porewater.

The presence of sorbed nitrate ion (a strong oxidant) on an amine-based anion exchange resin may be subject to gradual exothermic gas-evolving decomposition reactions; this effect has been noted for dried resin from strongly acidic medium ${ }^{24,25}$ but should be minimal for resin produced under alkaline conditions. Diluting the resin in the alkaline water-filled, microporous structure of grout should allow small amounts of gases and heat from chemical and radiolysis reactions (if any) to safely dissipate without damaging overpressurization of the binder matrix. ${ }^{\prime \prime}$

\section{Leachability Testing Using the Cured Grout Specimens}

The ANS-16.1 lcachability index for nitrate ion determined for each grout formulation after its 43-day cure is given in Table 3. The leachability index was similar for all five grout preparations (mean \pm standard deviation, $9.8 \pm 0.3$ ) and greatly exceeded the guidance value of a leachability index of 6 . (See Table 1.)

Similar testing for nitrate-containing sludge waste solidified in OPC/BFS/fly ash grout yielded leachability indices of 6 to 7 (Refs. 15,18); the greater leachability indices for nitrate ion from ion-exchange resin solidified in grout suggests that nitrate ion is not readily displaced from the resin beads within the grout matrix. 
TABLE 3-Results of the leachability and freezing/thawing tests.

\begin{tabular}{ccc} 
Blend Number $^{a}$ & $\begin{array}{c}\text { Leachability Index } \\
\text { for Nitrate Ion }\end{array}$ & $\begin{array}{c}\text { Cumulative Mass Loss Grout } \\
\text { (Freczing/Thawing Procedure) }\end{array}$ \\
\hline & & \\
2 & $9.7 \pm 0.1$ & $0.92 \%(w / w)$ \\
3 & $9.8 \pm 0.1$ & $1.79 \%(w / w)$ \\
4 & $9.9 \pm 0.2$ & $0.57 \%(w / w)$ \\
5 & $10.1 \pm 0.1$ & $4.19 \%(w / w)$ \\
& $9.5 \pm 0.0$ & $6.24 \%(w / w)$ \\
\hline
\end{tabular}

${ }^{a}$ Table 2 defines the dry-blend mix compositions used in the preparation of these grout blends.

${ }^{b}$ These values are a mean \pm 1 standard deviation for three replicate samples.

Representative data for nitrate ion leaching from a cured grout-based IER waste form are given in Fig. 1. Since a plot of the cumulative fraction of contaminant leached $\left(a_{n} / A_{n}\right)$ versus the square root of time (Equation 1) should be linear for a simple diffusiun-limited process, we concluded that the main transport phenomenon for nitrate ion is consistent with a diffusional process.

Due to the greater affinity of the anion exchange resin for $\mathrm{TcO}_{4}$ and the inherent low leachability of Tc in BFS-based grout, we concluded the release rate for Tc-99 should be very small.

\section{Freezing/Thawing Testing}

Weight loss data from the freezing/thawing test protocol are given in Table 3 for the grout specimens. All specimens passed the criterion ( $<20$ percent weight loss), with a maxirnum loss of only 6 percent for formulation \#5. After the testing protocol, only minor surface cracks were observed, with no significant waste form deterioration.

\section{Immersion Testing}

The cylindrical cured grout specimens immersed in distilled water for the recommended 90 days (and then for a longer period of time) showed no visible signs of deterioration. After approximately 200 days of immersion, the duplicate specimens subjected to compressive strength testing (ASTM procedure $\mathrm{C} 39$ ) indicated the following columnar compressive strengths: blend \#1 (4560 and $3170 \mathrm{kPa}$ ), blend \#2 (4150 and $2930 \mathrm{kPa}$ ), blend \#3 (4530 and $2820 \mathrm{kPa}$ ), blend \#4 (5520 and $3920 \mathrm{kPa}$ ), and blend \#5 (6110 and $3770 \mathrm{kPa}$ ). These values are similar for all specimens (average value $4080 \mathrm{kPa}$ ), and easily exceeded the $414 \mathrm{kPa}$ (60 psi) guidance value listed earlier in Table 1. 


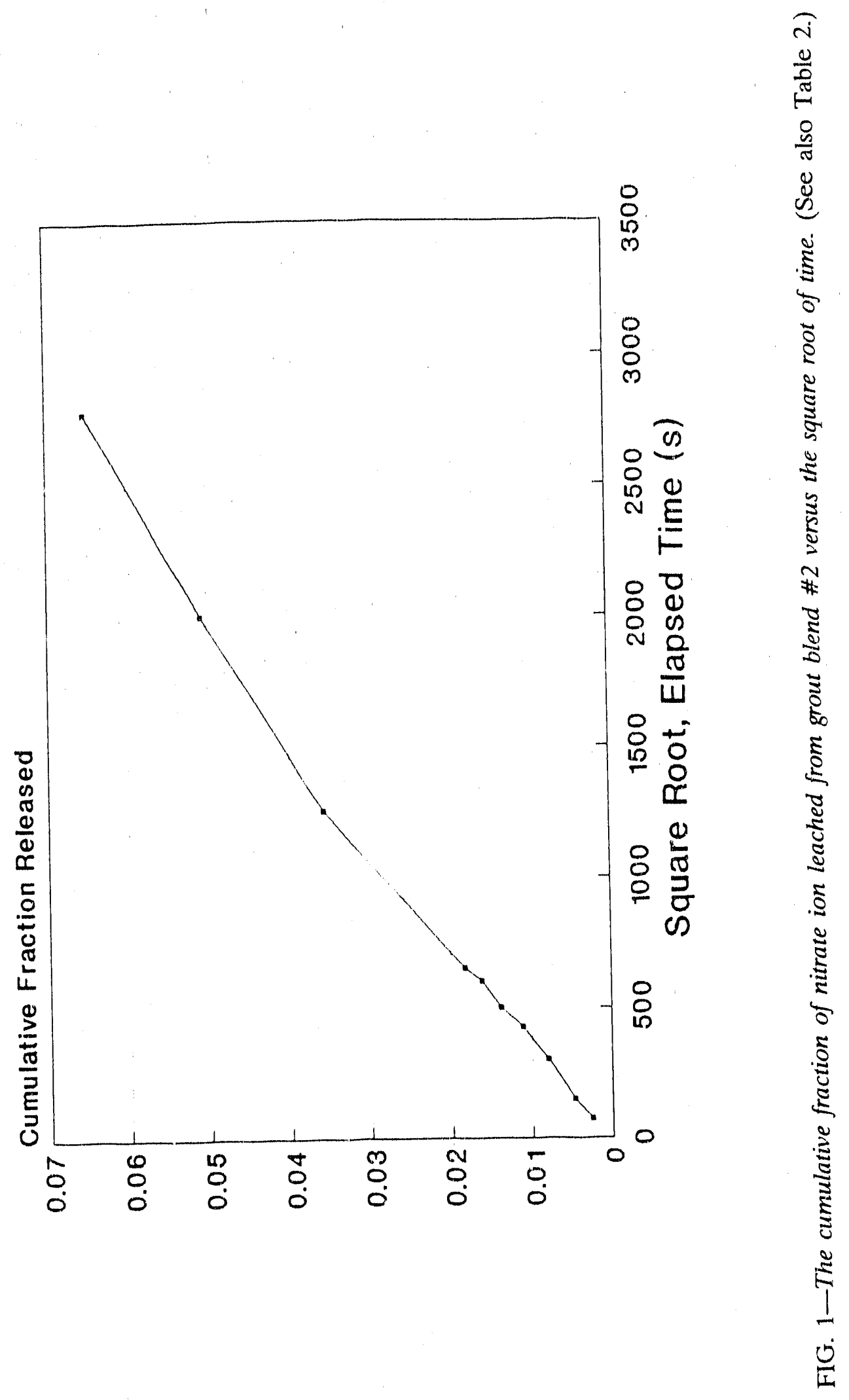




\section{Wetting/Drying Testing}

Data from the wetting/drying testing on the grout preparations are presented ir. "1 able 4. Blends \#1 and \#2 containing bentonite failed the mass loss criterion (a cumulative weight loss of less than 20 percent) within one or two testing yycles. Figure 2 illustrates the physical deterioration of a 2 -in. cube of grout prepared from/blend \#1, after water immersion in the first cycle of the wetting/drying procedure. B/ends containing attapulgite performed better in this testing, although blend \#3 (with added amorphous silica) and blend \#5 (with added ASTM Class F fly ash) failed after several cycles (11 cycles for blend \#3 and between cycles 7 and 8 for blend \#5). The performance for blend \#4 (and a repeat pour, blend $4 R$ ) was superior, with a cumulative weight loss of a about 1.6 percent after twelve cycles of testing. Blend \#7, without added silica or clay, demonstrated an intermediate cumulative weight loss.

The wetting/drying procedure was applied to a section prepared from the VERI ${ }^{\star}$ resin stabilized waste form; the cumulative weight loss recorded was 1.1 percent after twelve cycles of testing.

\section{Fire Accident Scenario Testing}

The results of our fire accident scenario testing are summarized in Table 5; most of the observed weight loss was attributed to waste form dehydration, although some binder may have melted and been lost from the VERI ${ }^{*}$-stabilized mixed bed resin sample. (See Fig. 3.)

\section{Conclusions}

We demonstrated that beaded anion exchange resins can be incorporated with a moderate waste loading (approximately 40 percent, by volume) into a grout matrix with good waste form integrity, as judged by our freezing/thawing and immersion testing. (No test specimens failed.) The wetting/drying procedure we also employed was a more scivere performance test for these waste forms; only two formulations tested in this investigation passed the success criterion (namely, a g-out prepared from a dry binder containing 90 percent BFS and 10 percent Type I-II OPC and a grout prepared from a dry binder blend containing 75 percent BFS, 10 percent Type I-II OPC, and 15 percent attapulgite-150 drilling mud). Th- improved performance toward the wetting/drying protocol demonstrated by the grouts containing the attapulgite suggests that the fibrous morphology of this additive may have imparted a physical advantage when the waste forms were subjected to the swelling and shrinking of the matrices. 


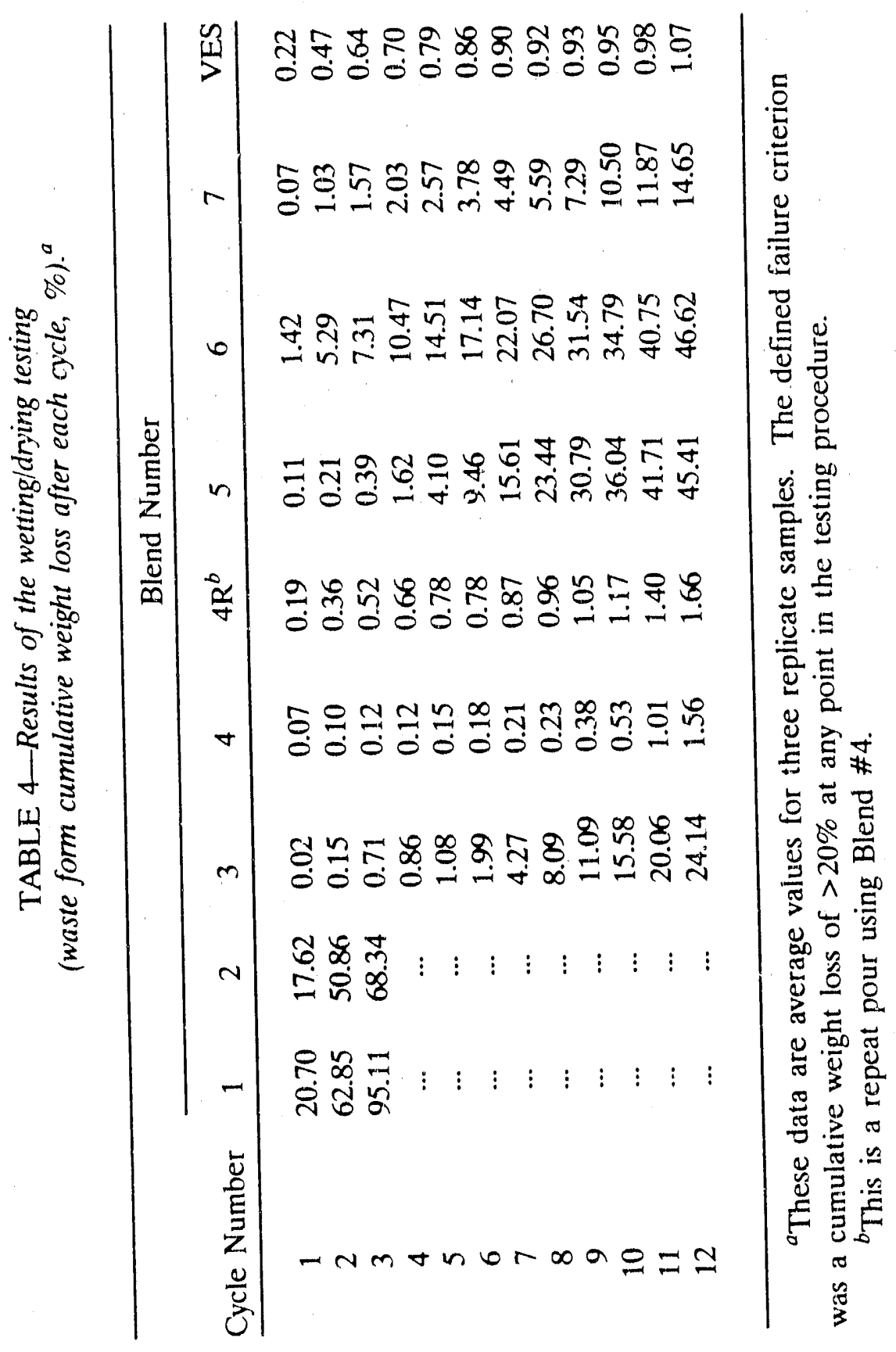




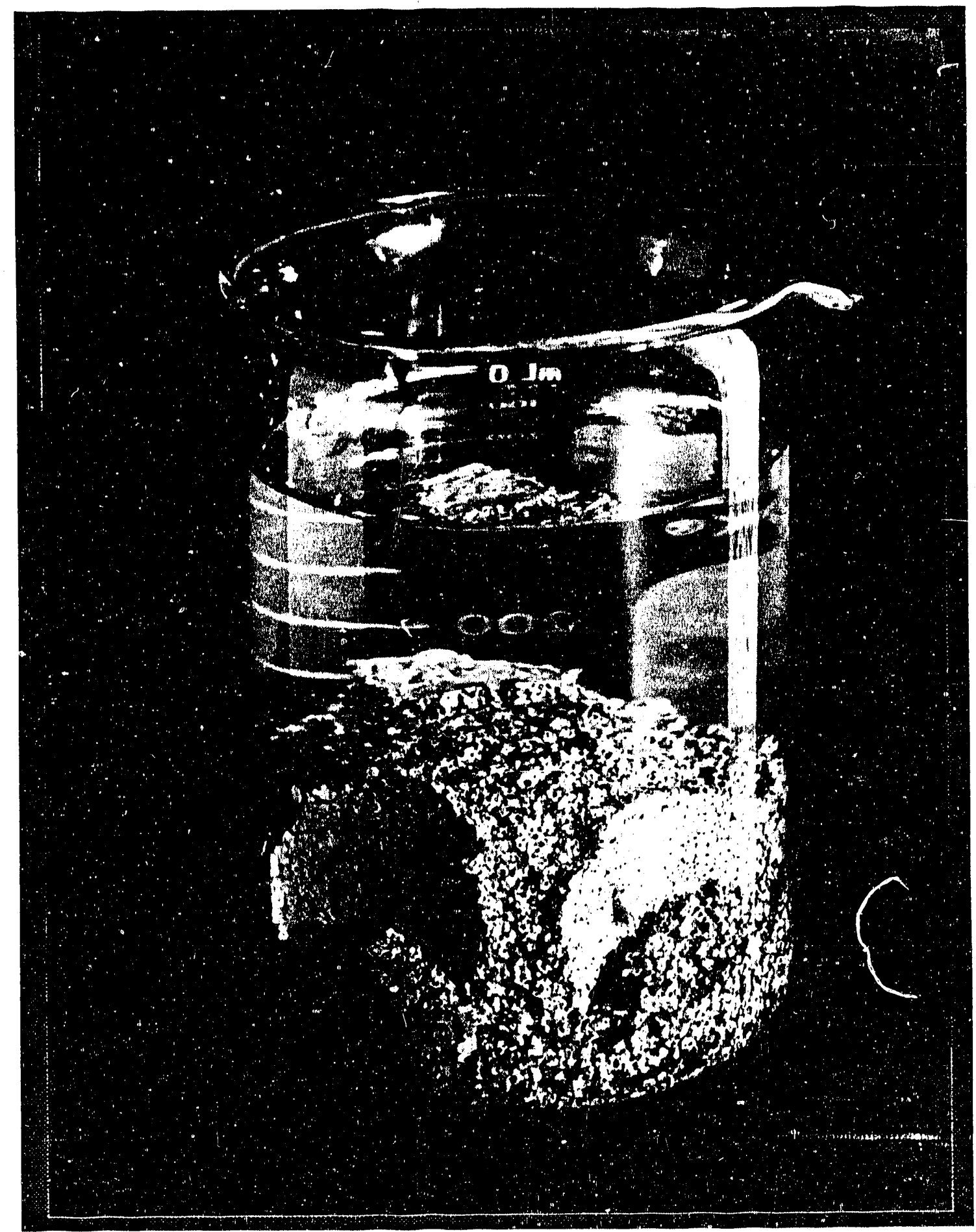

FIG. 2-The physical deterioration of a 2-in. cube of grout prepared from blend \#1, after water immersion in the first cycle of wetting/drying testing. (See also Table 2.) 
TABLE 5-Results of the fire accident scenario testing (waste form weight loss after 10-min fuel oil fire).

\begin{tabular}{|c|c|c|c|}
\hline Sample & Starting Weighı, g & Final Weight, $\mathrm{g}$ & Weight Loss, $\%$ \\
\hline Grout/SBR-NO ${ }_{3}$ Resin & 189.07 & 161.38 & 14.6 \\
\hline VERI ${ }^{\oplus} / \mathrm{SBR}-\mathrm{NO}_{3}$ Resin & 52.47 & 47.58 & 9.3 \\
\hline VERI ${ }^{\star} /$ Mixed Bed Resin & 47.88 & 15.10 & 68.3 \\
\hline
\end{tabular}

Limited testing using resin solidified in vinyl ester styrene suggests that the commercially prepared surrogate waste form performs very satisfactorily against the wetting/drying test criterion. Important properties for resin embedded in this type of organic matrix include fire resistance, leachability, radiation stability, compressive strength, and swelling behavior. ${ }^{5}$ Vendor-supplied information suggests that the VERI ${ }^{\star}$ process performs well by these criteria. ${ }^{2 \gamma}$ VERI $^{\star}$-solidified IER loaded with nitrate resin was subjected to exposure to a fuel oil fire for $10 \mathrm{~min}$; no significant acceleration of the fire was observed, although an occasional s rface bead was observed to flare. The waste form showed surface charring, but the bulk material did not burn. A grout waste form subjected to the burn test remained intact but did show surface cracks. (See Fig. 4.)

\section{Acknowledgments}

We would like to thank E. W. McDaniel of the Oak Ridge National Laboratory for his valuable input on the selection and behavior of clay additives in grout. We also want to thank R. A. Bruce, H. E. Filter, and C. E. Jenson for demonstrating the VERI process with our resin sample.

\section{References}

1. Le Bescop, P., Bouniol, P., and Jorda, M., Scientific Basis for Nuclear Waste Management XIII, V. M. Oversby and P. W. Brown, Eds., Materials Research Society, 1990, pp. 183-189.

2. Sandrelli, G., Terrani, S., and Sangalli, G., Proceedings of the 1989 Joint International Waste Management Conference, 1989.

3. Otoda, T. et al., Waste Management '87, Vol. 3, R. G. Post, Ed., 1987, pp. 117-122.

4. Ghattas, N. K., Eskander, S. B., and Ikladious, N. E., Radioactive Waste Management and the Nuclear Fuel Cycle, Vol. 7, No. 1, 1986, p. 13.

5. Patek, P. R. M. et al., Radioactive Waste Management, Vol. 2, International Atomic Energy Agency, Vienna, 1984, pp. 171-187. 

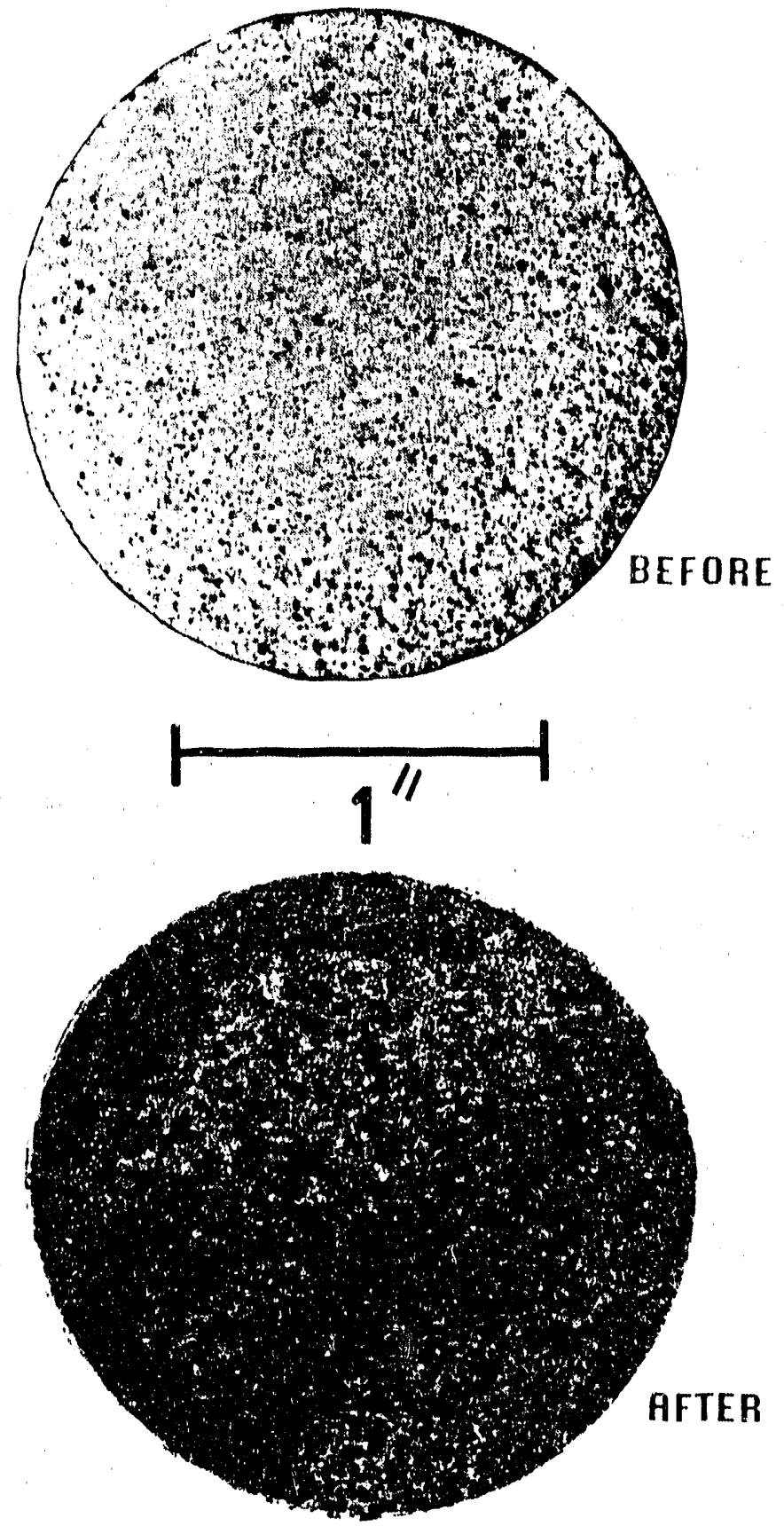

FIG. 3-The appearance of cross-sectional disks of nitrated resin in vinyl ester styrene matrix both before and after subjection to a fuel oil fire for an intenval of $10 \mathrm{~min}$. 


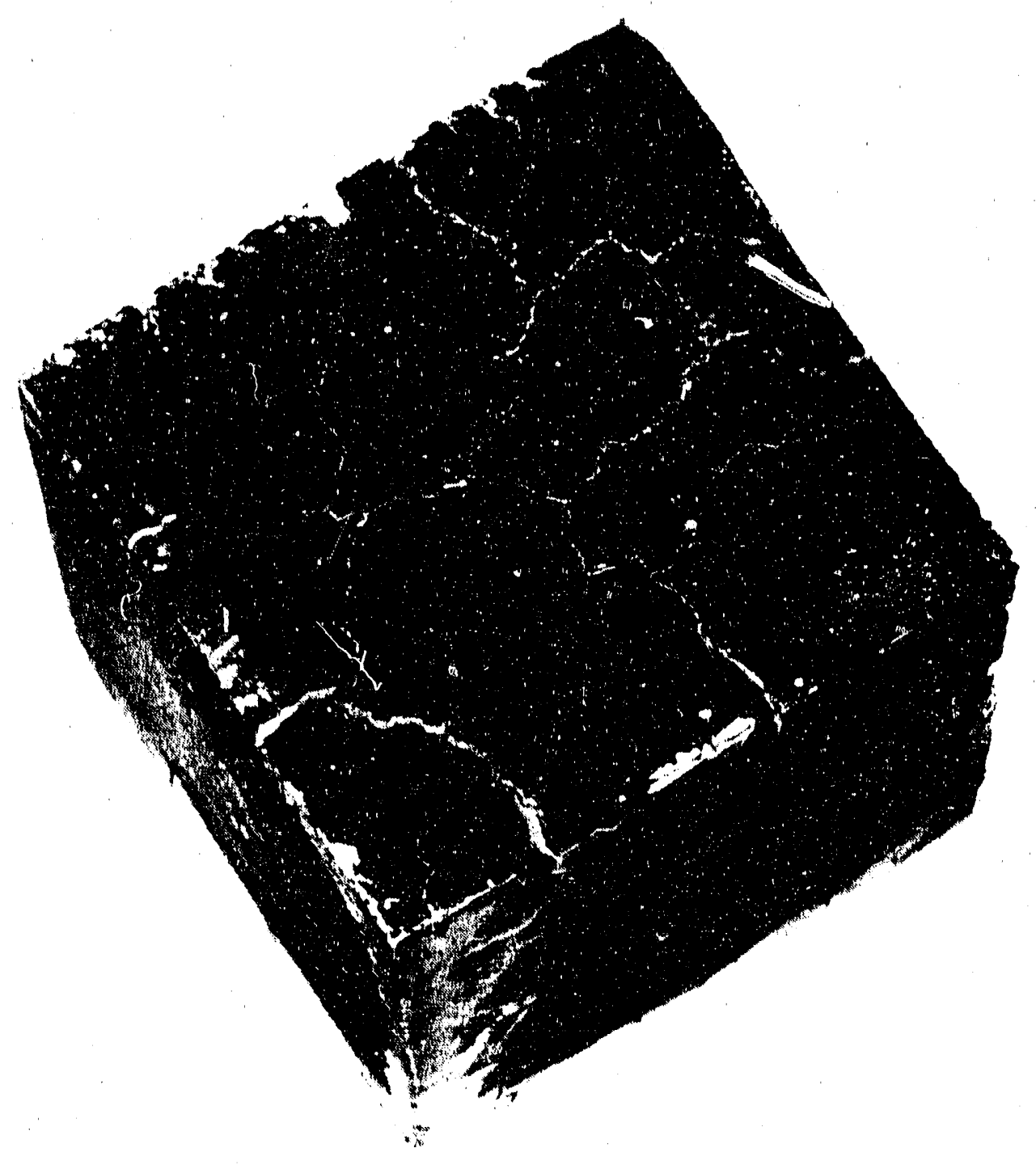

FIG. 4-The appearance of a 2-in. cube of grout-stabilized nitrated resin after subjection to a fuel oil fire for an interval of $10 \mathrm{~min}$. 
6. Workshop on Cement Stabilization of Low-Level Radioactive Waste, Report NUREG/CP-0103, U.S. Nuclear Regulatory Commission, Washington, D.C., 1989.

7. Duquesne, J. and Jaouen, C., Proceedings of the International Conference on Nuciear Fuel Reprocessing and Waste Management (RECOD '87), August 1987.

8. Joauen, C. and Vigreux, B., Proceedings of Nuclear and Hazardous Waste Management (Spectrum '88), American Nuclear Society, 1988, pp. 105-108.

9 Arnold, G. et al., Solidification of Ion-Exchange Resin Wastes, Report BNL-51615, Brookhaven National Laboratory, Upton, New York, 1982.

10. Soo, P., Milian, L. W., and Piciulo, P. L., The Leachability and' Mechanical Integrity of Simulated Decontamination Resin Wastes Solidified in Cement and Vinyl Ester-Styrene, Report NUREG/CR-5153, U.S. Nuclear Regulatory Commission, Washington, D.C., 1988.

11. Lee, D. J., Griffiths, C. J., and Fenton, A., "The Development of Cement Formulations for Radioactive Waste Encapsulation, manuscript submitted for publication in the Proceedings of ASTM '90.

12. Acox, 'T. A., Proceedings 4th DOE Environmental Protection Information Meeting (CONF-821215-DE83017117), August 1983, pp. 77-85.

13. Saraceno, A. J., The Control of Technetium at the Portsmouth Gaseous Diffusion Plant, Report GAT-2010, Goodyear Atomic Corporation, Piketon, Ohio, November 1981.

14. Bostick, W. D. and Evans-Brown, B. S., Sorptive Removal of Technetium from Heaivy Metals Sludge Filtrate Containing Nitrate Ion, Report K/QT-160, Martin Marietta Energy Systems, Inc., Oak Ridge, Tennessee, 1988.

15. Bostick, W. D. et al., Emerging Technologies in Hazardous Waste Management, D. W. Tedder and F. G. Pohland, Eds., American Chemical Society, 1990, pp. 345-367.

16. Dyer, A. and McGinnes, D. F., Organic Resin Anion Exchangers for the Treatment of Radioactive Wastes, Department of the Environment Report No. DOE/RW/88-106, London, 1988.

17. Rahman, A. A. and Glasser, F. P., Cements in Radioactive Waste Management: Characterization Requirements of Cement Products for Acceptance and Quality Assurance Purposes, Report EUR.1083-EN, Commission of the European Communities, Luxembourg, 1987.

18. Bostick, W. D. et al., Blast Furnace Slag-Cement Blends for the Immobilization of Technetium-Containing Wastes, Report K/QT-203, Martin Marietta Energy Systems, Inc., Oak Ridge, Tennessee, 1988.

19. Tallent, O. K. et al., Proceedings of the Materials Research Society Symposium, Materials Research Society, Vol. 112, Pittsburg, Pennsylvania, 1988, p. 23. 
20. Brodda, B. G., Science of the Total Environment, Vol. 69, No. 69, Netherlands, 1988.

21. Measurement of the Leachability of Solidified Low-Level Radioactive Wastes by a Short-Term Test Procedure, ANSI/ANS-16.1, American Nuclear Snciety, 1986.

22. MacKay, D. and Paterson, S., Environmental Science Technology, Vol. 18, 1984, p. $207 \mathrm{~A}$.

23. Anders, E., The Radiochemistry of Technetium, National Academy of Sciences monograph NAS-NS 3021, November 1960.

24. Van Slyke, W. J., Final Report of Chemical Safety for Technetium-99 Recovery by Anion Exchange, Report BNWL-476, Battelle Pacific Northwest Laboratory, Richland, Washington, 1967.

25. Cleveland, J. M., The Chemistry of Plutonium, Goidon and Breach Scientific Publishers, New York, 1970, p. 157.

26. Filter, Harold et al., The Dow Waste Solidification Process for Low-Level Radioactive Waste, U.S. NRC. Topical Rujort DNS-RSS-200-P, U.S. Nuclear Regulatory Comrnissio7, W'ashington, D.C., 1990. 

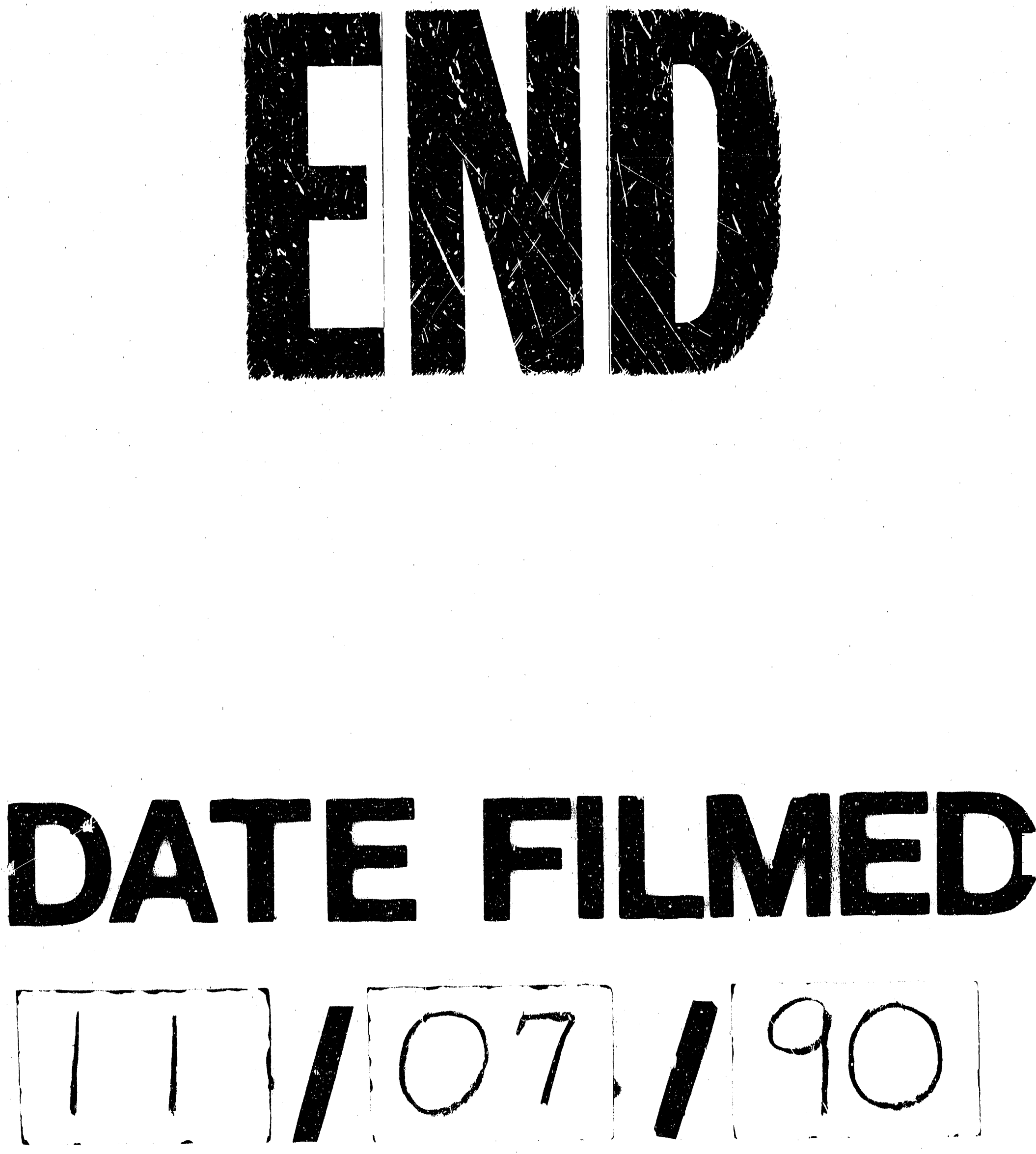
